\title{
Saberes emergentes do período pandêmico no curso de pedagogia: percepções discentes sobre o uso de tecnologias de informação e comunicação na educação
}

\author{
Emerging knowledge from the pandemic period in the pedagogy course: students' \\ perceptions about the use of information and communication technologies in education
}

\author{
Conocimientos emergentes del período pandémico en el curso de pedagogía: \\ percepciones estudiantiles sobre el uso de las tecnologías de la información y \\ comunicación en la educación
}

\author{
Moana Meinhardt ${ }^{1}$ \\ Douglas $\mathrm{Vaz}^{2}$ \\ Hildegard Susana Jung ${ }^{3}$
}

\section{Resumo}

Para muitos setores da sociedade, o ano de 2020 foi um divisor de águas no que se refere aos percursos e perspectivas até então adotados. Na educação básica, a pandemia mostrou uma fragilidade no que se refere à utilização de tecnologias digitais, ocasionada por falta de estrutura e/ou lacunas na formação de professores. Na educação superior, em pouco tempo professores tiveram que "virar a chave", reorganizando o processo ensino-aprendizagem, mediante a inserção de tecnologias de informação e comunicação que garantissem a interação com os estudantes e entre estes. Diante dessa situação, o presente estudo de caso teve como objetivo analisar os aspectos da formação docente que, na concepção dos estudantes de um curso de Pedagogia presencial de uma universidade comunitária da região metropolitana de Porto Alegre, RS, foram potencializados a partir da união entre educação e tecnologias, durante a pandemia da Covid-19. O levantamento dos dados foi realizado a partir do envio de questionário on-line aos acadêmicos. A partir da análise, verifica-se a aceleração, por conta da pandemia, da inserção e utilização das tecnologias de informação e comunicação nas diferentes disciplinas do curso de Pedagogia; a desacomodação dos docentes no que se refere às suas práticas pedagógicas; e a suscitação de novos saberes docentes alinhados às demandas da educação contemporânea.

Palavras-chave: formação de professores; tecnologias de informação e comunicação; aprendizagem; inovação; docência.

\begin{abstract}
${ }^{1}$ Doutora em Educação pela Universidade La Salle. Professora do curso de Pedagogia e Assessora Pedagógica da Universidade La Salle. E-mail: moameinhardt@gmail.com. ORCID: https://orcid.org/0000-0001-6422-1513.

${ }^{2}$ Doutorando em Educação pela Universidade La Salle. Professor do curso de Pedagogia e Coordenador Pedagógico Adjunto do Setor Pedagógico da Educação a Distância da Universidade La Salle. E-mail: douglasv.edu@ gmail.com. ORCID: https://orcid.org/0000-0002-3950-0120.

${ }_{3}$ Doutora em Educação pela Universidade La Salle. Professora do curso de Pedagogia e Coordenadora do Programa de Pós-Graduação em Educação da Universidade La Salle Canoas. E-mail: hildegardsjung@gmail.com. ORCID: https://orcid.org/0000-0001-5871-3060.
\end{abstract}


For many sectors of society, the year 2020 was a watershed in terms of the paths and perspectives adopted so far. In basic education, the pandemic showed a weakness with regard to the use of digital technologies, caused by a lack of structure and/or gaps in teacher training. In higher education, in a short time, teachers had to "turn the key", reorganizing the teachinglearning process, through the insertion of information and communication technologies that guaranteed interaction with students and between them. Given this situation, the present case study aimed to analyze the aspects of teacher education that, in the conception of students of a classroom Pedagogy course at a community university in the metropolitan region of Porto Alegre, RS, were enhanced from the union between education and technologies during the Covid-19 pandemic. Data collection was carried out by sending an online questionnaire to students. From the analysis, there is an acceleration, due to the pandemic, of the insertion and use of information and communication technologies in the different disciplines of the Pedagogy course; the lack of accommodation of teachers with regard to their pedagogical practices; and the raising of new teaching knowledge aligned with the demands of contemporary education.

Keywords: teacher education; information and communication technologies; learning; innovation; teaching.

\section{Resumen}

Para muchos sectores de la sociedad, el año 2020 marcó un hito en cuanto a los caminos y perspectivas adoptados hasta hoy. En educación básica, la pandemia mostró una debilidad en cuanto al uso de tecnologías digitales, provocada por la falta de estructura y / o brechas en la formación docente. En la educación superior, en poco tiempo, los docentes debieron "girar la llave", reorganizando el proceso de enseñanza-aprendizaje, mediante la inserción de tecnologías de la información y la comunicación que garantizaran la interacción con los estudiantes y entre ellos. Ante esta situación, el presente estudio de caso tuvo como objetivo analizar los aspectos de la formación docente que, en la concepción de los estudiantes de un curso de Pedagogía presencial en una universidad comunitaria de la región metropolitana de Porto Alegre, RS, se potenciaron desde la unión entre educación y tecnologías durante la pandemia Covid-19. La recolección de datos se realizó mediante el envío de un cuestionario en línea a los estudiantes. A partir del análisis se percibe que se acelera, debido a la pandemia, la inserción y uso de las tecnologías de la información y la comunicación en las diferentes disciplinas del curso de Pedagogía; preocupación de los docentes con respecto a sus prácticas pedagógicas; y la generación de nuevos conocimientos docentes alineados con las demandas de la educación contemporánea.

Palabras clave: formación del profesorado; tecnologías de la información y la comunicación; aprendizaje; innovación; docencia.

\section{Introdução}

A pandemia do novo Coronavírus impactou todos os setores da sociedade, trazendo inúmeros desafios a cada um deles. As medidas de distanciamento social atingiram 
diretamente o setor educacional com a suspensão das aulas presenciais em todos os níveis e instituições de ensino, as quais tiveram que promover inúmeras adaptações, em um curto período de tempo, a fim de garantir a manutenção das aulas por meio da utilização de recursos tecnológicos.

No caso específico das instituições de ensino superior, o enfrentamento deste desafio requereu agilidade e mobilização de toda a comunidade acadêmica e, em especial, dos docentes e estudantes que precisaram se adaptar frente à nova realidade com responsabilidade e comprometimento com a qualidade da formação. Na sintetização e enfrentamento deste imprevisível contexto,

Levar a sério o Ensino Superior requer cuidado com aquilo que faremos neste período emergencial e após a emergência; requer, também, decisões de acordo com as concepções que definem esse nível de ensino. Apesar de se tratar de uma situação emergencial, o ensino não pode constituir prática sem planejamento, de improviso e com características meramente burocráticas. É importante que a adoção do ensino remoto envolva oportunidades para planejar condições de ensino que promovam o desenvolvimento de aprendizagens de Ensino Superior, mais do que de adesão e repetição de conteúdos. (GUSSO et al, 2020, p. 9).

Ao mesmo tempo, sabemos que o uso de tecnologias de informação e comunicação no ensino superior e, especialmente, nos cursos de formação inicial de professores, mais especificamente, no curso de Pedagogia que constitui o campo de investigação do presente estudo de caso, não deveria ser uma novidade. No entanto, sabemos também que a inserção destas no planejamento docente ainda anda a passos lentos.

O contexto da pandemia exigiu, após o início das atividades letivas do primeiro semestre de 2021, uma mudança drástica de planejamento no que se referia às atividades acadêmicas dos cursos de licenciatura. Para tanto, foi necessária a apropriação, em pouco tempo, de diversos recursos tecnológicos que permitissem a interação entre acadêmicos, professores e alunos. De acordo com Vaz, Meinhardt e Fossatti (2020), ao narrarem a experiência de uma universidade que, de uma semana para outra transformou todas as suas atividades pedagógicas de sala de aula para o sistema de ensino remoto, “[...] cada vez mais, a cultura digital se consolida nas ações propostas pela Universidade, alinhando-se às demandas que emergem na sociedade contemporânea" (VAZ, MEINHARDT e FOSSATTI, 2020, p. 20).

Voltando ao contexto da pesquisa em tela, para a apropriação dos recursos 


\section{OO DEVIR EDUCAÇÃO}

ISSN: 2526-849X

tecnológicos, foram desenvolvidas diversas ações que impactaram o processo formativo dos acadêmicos matriculados no curso de Pedagogia presencial, durante a pandemia. Considerando o exposto, o presente estudo buscou responder ao seguinte problema de pesquisa: Quais aspectos da formação de estudantes do curso de Pedagogia presencial de uma universidade comunitária da região metropolitana de Porto Alegre, RS, se viram potencializados a partir da união entre educação e tecnologias durante a pandemia da Covid19, na concepção desses acadêmicos?

Isso posto, definiu-se como objetivo geral analisar os aspectos da formação docente que, na concepção dos estudantes de um curso de Pedagogia presencial de uma universidade comunitária da região metropolitana de Porto Alegre, RS, foram potencializados a partir da união entre educação e tecnologias, durante a pandemia da Covid-19.

Em decorrência, estabeleceram-se como objetivos específicos:

- Discutir sobre o papel da tecnologia na educação durante a pandemia da Covid-19.

- Problematizar a formação inicial docente a partir do novo contexto educacional dos anos 2020-2021.

- Investigar os saberes docentes necessários à educação contemporânea.

Com relação à arquitetura do texto, na sequência desta introdução encontramos o percurso metodológico da pesquisa, seguido do referencial teórico que traz alguns dos aportes utilizados na investigação, a análise e discussão dos dados e, finalmente, as considerações finais e as referências que embasaram o estudo.

\section{Percurso Metodológico}

O presente estudo possui abordagem qualitativa. Alves, ao explicar a abordagem qualitativa, ressalta que:

Para os "qualitativos" a realidade é uma construção social da qual o investigador participa, e portanto, os fenômenos só podem ser compreendidos dentro de uma perspectiva holística, que leve em consideração os componentes de uma dada situação em suas interações e influências recíprocas, o que exclui a possibilidade de se identificar relações lineares de causa e efeito e de se fazer generalizações do tipo estatístico. (ALVES, 1991, p. 55). 


\section{OO DEVIR EDUCAÇÃO}

ISSN: 2526-849X

O principal objetivo da pesquisa qualitativa, segundo Zanelli (2002, p. 83) “[...] é buscar entender o que as pessoas aprendem ao perceberem o que acontece em seus mundos". A pesquisa qualitativa apresenta como uma de suas vantagens a produção de "[...] uma análise detalhada e exata de alguns casos pode ser produzida, e os participantes têm muito mais liberdade para determinar o que é importante para eles e para apresentá-los em seus contextos" (FLICK, 2013, p. 25).

Como procedimento técnico optou-se pelo desenvolvimento de um estudo de caso que, segundo Patton (2002), tem como propósito reunir informações sistemáticas e detalhadas sobre determinado fenômeno. Já segundo Yin, este tipo de pesquisa “[...] é usado em muitas situações, para contribuir ao nosso conhecimento dos fenômenos individuais, grupais, organizacionais, sociais, políticos e relacionados" (YIN, 2015, p. 4).

O estudo teve como campo empírico uma universidade comunitária da região metropolitana de Porto Alegre/RS que oferece o curso de Pedagogia na modalidade presencial. Os sujeitos integrantes do estudo foram os matriculados no Curso de Pedagogia presencial que, durante o ano de 2020, participaram das aulas on-line, mediadas pelo uso de tecnologias de informação e comunicação, em decorrência da suspensão das atividades presenciais em atendimento às medidas de distanciamento social.

O curso de Pedagogia foi escolhido, por se tratar do locus da formação dos professores da Educação Infantil e dos Anos Iniciais do Ensino Fundamental, etapas da Educação Básica que, durante a pandemia da Covid-19, sentiram fortemente a necessidade da inserção das tecnologias de comunicação e informação no processo ensino-aprendizagem de um lado e a falta de preparo para tal de outro, ressaltando a importância de contemplar tais saberes no percurso formativo do pedagogo.

A coleta de dados foi realizada por meio da aplicação de um questionário on-line com questões objetivas e discursivas referentes ao uso de tecnologias de informação e comunicação durante o período de realização de aulas remotas no curso de Pedagogia. Foram enviados questionários a aproximadamente 100 estudantes matriculados em disciplinas de graduação do curso de Pedagogia, dos quais obtivemos o retorno de 23 estudantes.

\section{A formação inicial docente: contingências na contemporaneidade}


A formação docente tem sido foco constante de estudos e debates em diferentes fóruns da sociedade aliada à necessidade de qualificação da educação básica oferecida no Brasil. Neste contexto, a pandemia acabou por expor ainda mais algumas fragilidades, dentre elas, a falta de preparo de muitos professores para a utilização de tecnologias de informação e comunicação no processo ensino-aprendizagem.

As Diretrizes Curriculares Nacionais para o curso de Pedagogia (BRASIL, 2006), responsável pela formação de professores para atuação na educação infantil e nos anos iniciais do ensino fundamental, apontam, dentre uma lista de competências, que os egressos do curso deverão estar aptos a: "VII - relacionar as linguagens dos meios de comunicação à educação, nos processos didático-pedagógicos, demonstrando domínio das tecnologias de informação e comunicação adequadas ao desenvolvimento de aprendizagens significativas.".

Para tanto, na formação inicial dos professores, não basta instrumentalizar os futuros docentes para o uso de recursos tecnológicos. Faz-se necessária a adoção de metodologias que promovam a utilização de mídias e ferramentas digitais associadas à uma prática críticoreflexiva, à resolução de problemas, ao trabalho em equipe, ao desenvolvimento de práticas investigativas e criadoras e à capacidade de inovação. Neste sentido, Bacich ressalta que a formação do professor

[...] deve se pautar pela atividade criadora, reflexiva, crítica, compartilhada e de convivência com as diferenças, usando as mídias e as tecnologias como linguagem e instrumento da cultura, estruturantes do pensamento, do currículo, das metodologias e das relações pedagógicas (BACICH, 2018, p. 148).

Dessa forma, compreendemos que a formação inicial e continuada de educadores deve ser ressignificada, englobando aspectos como os supracitados, mas também promovendo uma (trans)formação humanizada, ética e alinhada às diversas contingências que emergem na contemporaneidade. Segundo Ghedin, “[...] a experiência docente é espaço gerador e produtor de conhecimento, mas isso não é possível sem uma sistematização que passe por uma atitude crítica do educador em face das suas próprias experiências" (GHEDIN, 2008, p. 81).

\section{O início da transformação: realidade pré-pandemia e o uso das Tecnologias de informação e comunicação}


Em consonância com os movimentos da sociedade e do modelo de Educação que se configura na contemporaneidade, percebe-se uma ressignificação do paradigma educacional no que se refere às concepções de docência, de ensino e de aprendizagem no contexto educacional. Segundo Fava, ao invés de nos referirmos sobre os professores e estudantes como ocupantes de papéis distintos, “[...] devemos agora considerá-los constituintes do processo de ensino-aprendizagem com um novo conjunto de regras que poucos de nós, educadores, entendemos e aceitamos por completo" (FAVA, 2014, p. 14).

O estudante do Século XXI apresenta-se como um sujeito cada vez mais conectado, nascido e criado no cerne da cultura digital. Nesse contexto, emerge a necessidade de repensarmos e construirmos, gradativamente, estratégias que preparem o docente a compreender e estar preparado para gerenciar este novo perfil de estudante. Para isso, é imprescindível a mobilização de competências que perpassam os contextos socioemocionais, tecnológicos, comunicacionais e de gestão da aprendizagem.

Segundo Fava, "o fato é que o professor centralizador do conhecimento, que rugia e comandava a sala de aula da forma que bem entendia, está pouco adaptado ao novo ambiente tecnológico e convergente dos recintos escolares". (FAVA, 2014, p. 14). Dessa forma, o autor infere que este processo começa a ser ressignificado na contemporaneidade:

[...] cada vez mais, a educação vai se tornando mais complexa, porque o foco está migrando da simples transmissão de conteúdos para dimensões menos integradas, conspícuas, perceptíveis, como as competências e habilidades intelectuais, emocionais e éticas. Ruem as paredes das salas de aula, aglutinando novos espaços de ensino-aprendizagem presenciais e virtuais. Alteram-se as atribuições do professor com a incorporação de novos papéis, como os de mediador, facilitador, gestor, mobilizador, motivador. (FAVA, 2014, p. 69).

O professor deve ser capaz, segundo Bacich e Moran (2018), de metamorfosear suas aulas em experiências de aprendizagem mais vivas e significativas para os estudantes da geração digital, “[...] cujas expectativas em relação ao ensino, à aprendizagem e ao próprio desenvolvimento e formação são diferentes do que expressavam nas gerações anteriores" (BACICH; MORAN, 2018, p. 10). Nessa perspectiva, "Conhecer tecnologia e saber interagir com ela é considerada quase uma necessidade na sociedade contemporânea" (SANTOS, 2016, p. 33). 
As tecnologias de informação e comunicação, gradativamente, vão ganhando espaço dentro e fora das escolas e universidades. Segundo dados da CEPAL/UNESCO, "en los últimos años, con la masificación de la conectividad sobre la base de Internet móvil y el incremento de dispositivos digitales más accesibles, las políticas han redirigido sus esfuerzos a la formación de habilidades digitales de las y los estudiantes" (2020, p. 5).

No que tange ao período pandêmico, cabe registrar que:

O momento tem sido de novas descobertas e possibilidades no campo educacional, uma vez que o uso das tecnologias, principalmente, das TICs têm ocupado um lugar primordial na transmissão e aquisição de conhecimentos, assumindo o lugar do espaço físico, a sala de aula, ainda que tal condição seja temporária, permitindo a interação, troca de informações, construção de diálogos e o fortalecimento da educação. (SOARES; COLARES, 2020, p.28)

Para Corradini e Mizukami, "Sem dúvida, a tecnologia permite ampliar o conceito de aula, estabelecendo um novo vínculo professor-aluno. Porém, é preciso ter claro o uso que se faz dela, visando à aprendizagem e não apenas à transmissão de informações." (2013, p. 90).

Nesse sentido, Perrenoud (2000) ao relacionar dez competências para ensinar, apontou, dentre elas: "Utilizar novas tecnologias". Ao discorrer sobre a importância desta competência para o exercício da docência na contemporaneidade, ressalta que precisa estar associada a uma mudança paradigmática, que desloca o foco central do ensino para a aprendizagem. Nesta perspectiva, os recursos tecnológicos não são utilizados como um auxílio ao ensino, para dar aulas cada vez mais bem ilustradas por recursos midiáticos, mas como possibilidade de criar situações de aprendizagem ricas, complexas e diversificadas.

Sobre este aspecto, Andrade e Sartori, afirmam:

Na relação cotidiana de sala de aula no século XXI, não é mais possível manter o foco de atenção dos estudantes por meio de palestras centradas no professor, ainda que incrementadas por ferramentas digitais como PowerPoint, Prezi, vídeos ou recursos de lousas digitais (ANDRADE E SARTORI, 2018, p. 179).

Percebe-se, portanto, que a "utilização pela utilização" das tecnologias em sala de aula, independentemente do nível de ensino ou da modalidade em questão, não é sinônimo de aprendizagem ou de inovação. Mais do que apenas disponibilizá-las aos estudantes, cabe ao professor desenvolver propostas que despertem o interesse, a descoberta e permitam uma 
aprendizagem significativa por parte dos estudantes. As tecnologias devem ser associadas a situações de aprendizagem que promovam a reflexão crítica dos estudantes, por meio da problematização e do desequilíbrio das estruturas cognitivas, tendo o professor como mediador.

Neste contexto, quando nos referimos à prática docente, precisamos ter em mente, de acordo com Franco (2012, p. 215) que esta não se estrutura espontaneamente, pois responde a um complexo esquema de multideterminações. "A prática que temos é, e sempre será, a possível nas atuais circunstâncias. [...] Ela muda quando pode mudar, quando quer mudar, quando seus protagonistas sentem e percebem a necessidade de mudança.".

Para tanto, em sua prática pedagógica, o professor precisa estar em contínuo processo de diálogo com o que faz, por que faz e como deve fazer. "É quase que intuitivo esse movimento de olhar, avaliar, refazer. Construir e desconstruir; começar de novo; acompanhar e buscar novos meios e possibilidades." (FRANCO, 2012, p. 170).

\subsection{Virar a chave da Tecnologia Educacional: o desafio emergente na pandemia}

Gradativamente, nos últimos anos, falar de tecnologia no ambiente educacional tornou-se um assunto cada vez mais cotidiano. Com a crescente disseminação dos recursos digitais, do acesso à Internet no Brasil e da utilização das mídias sociais, a sociedade contemporânea caminhava para um modelo cada vez mais conectado. As medidas de isolamento social demandadas pela pandemia da Covid-19, já haviam impactado em março de 2020, 167 países e mais de 1,4 bilhão de alunos em todo o mundo, segundo dados da UNESCO. Na maior parte dos casos, o currículo precisou ser reinventado em todos os níveis de ensino, abandonando os métodos tradicionais e sendo retomado em modelo remoto, virtual.

Segundo Ramos, Barragan e Masetto (2020), a interação presencial entre professor e estudantes em sala, bem como "[...] o horário de aula presencial medidos pelo tempo cronos, hoje não mais nos pertencem" (p. 14). As tecnologias de informação e comunicação, até então um recurso tido majoritariamente como complementar nos espaços de aprendizagem, apresentam-se como a única alternativa viável para continuidade dos processos de ensinoaprendizagem em todos os níveis de ensino. Segundo relatório emitido em 2020, 
Dado que la mayoría de los países han optado por la continuidad del proceso educativo mediante recursos en línea, el uso de Internet ofrece una oportunidad única: la cantidad de recursos pedagógicos y de conocimiento disponibles, así como las diferentes herramientas de comunicación proveen plataformas privilegiadas para acercar la escuela y los procesos educativos a los hogares y a los estudiantes en condiciones de confinamiento. (CEPAL/UNESCO, 2020, p. 5).

No entanto, o acesso a estes recursos ainda está distante da realidade de muitos sujeitos no país e no mundo. A pandemia da Covid-19 deflagrou uma sociedade amplamente díspar no que se refere à utilização destes recursos. Ao passo que muitas famílias possuíam a infraestrutura necessária para o acesso às aulas remotas, inúmeros foram os casos de fragilidade ou impossibilidade de acesso.

Outro ponto de alerta, já discutido e que requer atenção, prejudicou a "virada" de chave da educação remota: a formação de professores para o uso de tecnologias de informação e comunicação. Ainda segundo o relatório:

[...] el profesorado que cuente con competencias para usar las TIC en su práctica profesional dispone de mejores elementos para brindar una educación de calidad y para guiar eficazmente el desarrollo de las competencias del alumnado en materia de TIC. A pesar de la existencia de estos estándares, son aún limitados los casos de instituciones que los han adoptado para transformar sus procesos de formación docente inicial, a fin de preparar a las futuras generaciones de docentes en lo referente a las competencias necesarias para la educación del siglo XXI. (CEPAL/UNESCO, 2020, p. 7).

Em outras palavras, podemos perceber que o letramento digital não é uma realidade unânime, especialmente em países em desenvolvimento.

\section{Análise e discussão dos resultados}

Dos vinte e três estudantes que participaram do estudo e responderam o questionário, treze têm entre 18 e 24 anos de idade, cinco estudantes têm entre 25 e 29 anos e cinco estudantes têm entre 31 e 54 anos de idade.

No gráfico 1, é possível observar que os vinte e três estudantes estão divididos entre os oito semestres do curso, o que possibilitou traçar a visão dos estudantes do curso acerca das 


\section{OO DEVIR EDUCAÇÃO}

ISSN: 2526-849X

tecnologias de comunicação e informação que se encontram em diferentes momentos da trajetória formativa.

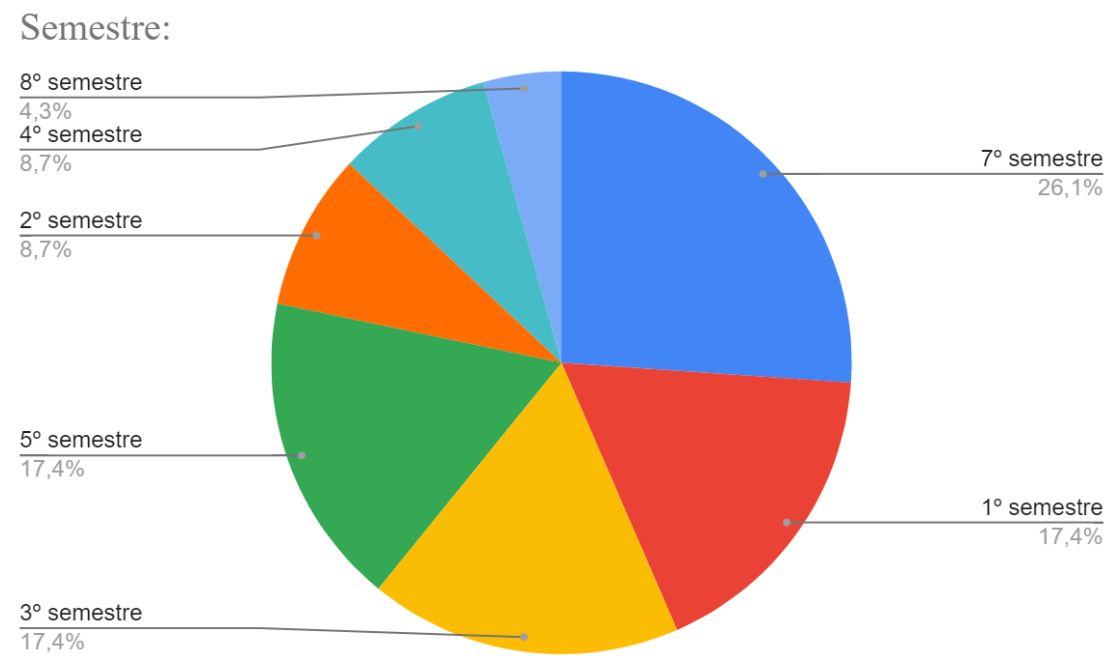

Figura 1: Distribuição dos acadêmicos por semestre. Fonte: Elaborado pelos autores (2021).

Já com relação à experiência profissional na docência, quase a metade dos estudantes $(48,7 \%)$ afirmou não possuir experiência docente, $21,7 \%$ possuem de 2 a 5 anos de experiência na docência e os demais apresentam diferentes períodos de experiência, como pode ser observado no gráfico 2, a seguir:

Contagem de Possui experiência docente? Caso possua, informe há quanto tempo.

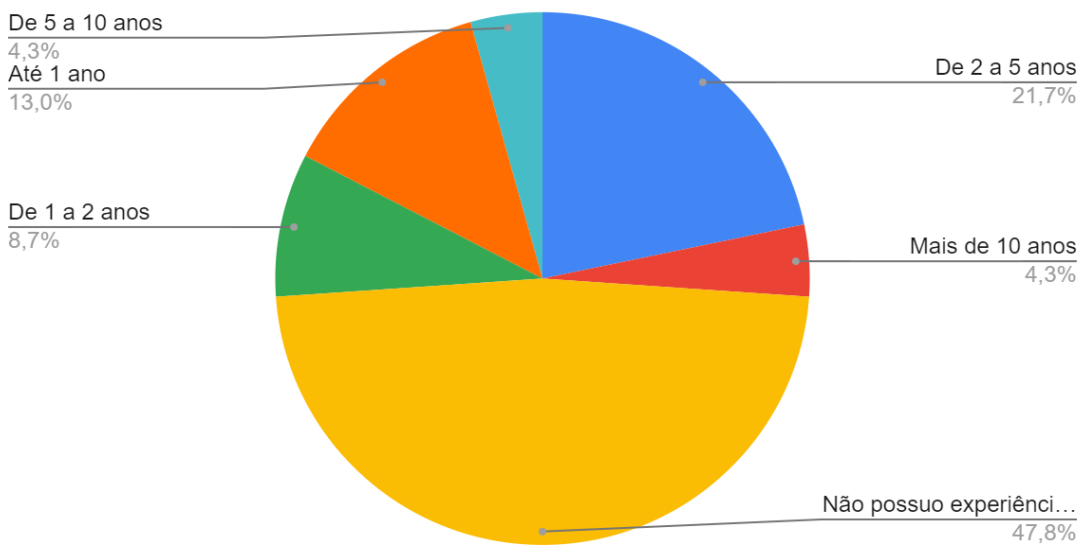

Figura 2: Tempo de experiência docente dos acadêmicos.

Fonte: Elaborado pelos autores (2021).

Revista Devir Educação, Lavras-MG. Edição Especial, p.227-246, Set./2021. 
Solicitou-se que os estudantes indicassem em uma escala de 1 a 5 o grau de importância das tecnologias na educação. Todos indicaram o grau 5, reconhecendo o relevante papel das tecnologias no campo educacional, aspecto que foi ratificado durante a pandemia e que pôde ser observado nas justificativas apresentadas, as quais apontaram o uso das tecnologias como recurso responsável pela manutenção das aulas durante o período de isolamento social.

Dentre as justificativas apresentadas, destaca-se também o reconhecimento do uso das tecnologias como meio para aproximar as pessoas, de forma segura: "A tecnologia foi uma extensão da sala de aula durante a pandemia, aproximando professores, alunos, escolas e famílias." Nesta mesma direção, outra estudante destaca: "Do contrário não teríamos como manter essa comunicação nesse nível, possibilitando que estejamos em contato direto com os professores, vendo-os e esclarecendo nossas dúvidas in loco. No momento da aula.". Neste contexto, as tecnologias foram reconhecidas como "[...] a principal ferramenta de comunicação, obtenção de informações e interação.".

O posicionamento dos estudantes evidencia o quanto

O uso das Tecnologias de Informação e Comunicação tem possibilitado a continuidade de demandas, exigências e novos percursos em torno dos processos educacionais [...]. É crescente a empregabilidade de aplicativos e ferramentas tecnológicas nas rotinas das instituições de ensino, com um número expressivo de sujeitos envolvidos por essa relação (Educação e Tecnologias). (SOARES; COLARES, 2020, p. 33).

Os estudantes de Pedagogia apontaram, ainda, recursos tecnológicos utilizados nas aulas remotas que consideraram relevantes para a sua formação docente, posicionando-se também sobre inovações pedagógicas percebidas a partir do uso destes. Dentre as respostas, cabe destacar a adoção de uma nova forma de utilização de velhos recursos, como o computador e o smartphone, que passaram a ser "[...] meios de estudos, trabalhos e comunicação em geral.". Este mesmo aspecto foi ratificado por outra estudante, que afirmou: "Os recursos utilizados muitas vezes já estavam presentes na nossa realidade, porém foram pensados e utilizados de maneira diferenciada - computador, celular, plataformas digitais...".

Isso posto, observa-se que as necessidades advindas da pandemia impulsionaram ações que permitiram reduzir as dificuldades em torno das TICs, "[...]construindo um 
caminho de contribuições, significados e valorização dos saberes. Momento em que a Educação apropria-se das ferramentas e produtos disponíveis na sociedade em prol da continuidade de suas necessidades e demandas." (SOARES; COLARES, 2020, p.34).

Deste modo, percebe-se que não são necessários recursos tecnológicos caros ou de ponta, mas repensarmos o uso daqueles que já estão à nossa disposição e são de fácil acesso pelos alunos e professores e que, muitas vezes, nas aulas presenciais são deixados de lado. Corradini e Mizukami ao se referirem ao computador e, em especial, à internet ressaltam que:

[...] se apenas considerados como meios de lazer ou de busca indiscriminada de informações, perdem o seu caráter educativo e passam a ser meros instrumentos de alienação. Contudo, ignorar sua importância na escola como ferramenta preciosa na construção do conhecimento, na aquisição de habilidades e na interação indivíduo-mundo/indivíduo-sociedade, é fechar as perspectivas do futuro para professor e aluno. (CORRADINI; MIZUKAMI, 2013, p. 90).

Dentre os recursos tecnológicos mais mencionados pelos estudantes estão aqueles que permitiram manter a comunicação e a interação entre professores e alunos, como acontecia nas aulas presenciais, porém com a mediação da tecnologias, tais como: videoconferência, chat, aplicativos de mensagens, que possibilitaram, no relato dos alunos, manter as pessoas próximas, mesmo durante o período de distanciamento social. Para uma das alunas, com as aulas ao vivo, por videoconferência se: "manteve o contato, a interação e a afetividade construída entre professores e alunos.".

A edição compartilhada de arquivos: documentos, apresentações, planilhas, lousa, dentre outros também esteve entre os recursos digitais mais citados. Nesse sentido, uma das estudantes relatou: "[...] as diversas opções de ferramentas [...] torna fácil a realização da aula remota, possivelmente ainda mais diversificada do que se estivéssemos presencialmente. Conheci ferramentas neste período que talvez não fossem utilizadas.".

As respostas dos alunos do curso de Pedagogia, evidenciaram o movimento dos docentes universitários que tiveram que repensar a organização de suas aulas, inserindo o uso de diferentes recursos tecnológicos, que acabaram por proporcionar, além da aprendizagem dos conteúdos específicos de suas disciplinas, o conhecimento sobre a utilização de tecnologias na educação de modo transversal às suas disciplinas.

Quanto à presença de aspectos inovadores nas aulas do curso de Pedagogia, durante o período da pandemia, com a realização das aulas remotas e o uso de recursos tecnológicos, os 


\section{OO DEVIR EDUCAÇÃO}

ISSN: 2526-849X

futuros professores destacaram alguns elementos que, na sua percepção, inovaram as aulas. Uma das estudantes afirmou: "Acredito que trouxe inovação, pois é uma forma de, inclusive, desenvolvermos nosso aprendizado em situações de tecnologia, porque nos permitimos, mesmo que com certo receio, inicialmente, a utilizar e praticar em programas, sites, etc. que, do contrário, não utilizaríamos.". Corroborando com esta afirmação, outra estudante destaca: "Muitos sites que foram utilizados nas aulas eu não conhecia e o Google Drive eu não sabia mexer, aprendi através das aulas também.".

O "receio" mencionado pela estudante, nas circunstâncias da pandemia, teve que ser superado tanto pelos professores universitários quanto pelos estudantes, que diante da necessidade de adaptar o processo ensino-aprendizagem, tiveram que conhecer recursos e ferramentas digitais, analisar suas possibilidades didáticas, inserindo-os no contexto da nova sala de aula.

Nesta perspectiva, referindo-se aos recursos de comunicação, outra estudante ressaltou: "Acredito que utilizá-los trouxe inovação sim, pois tivemos que transferir dinâmicas em sala de aula física que exigiam deslocamento e/ou agrupamento entre os estudantes, sendo assim, fizemos uso de recursos digitais [...] para ressignificar as tarefas colaborativas."

Percebemos, assim, por meio das respostas dos estudantes, que a suspensão das aulas presenciais, e a necessidade de encontrar meios de garantir a continuidade das aulas com a interação que estas requerem, impulsionaram o uso de recursos tecnológicos, o que anteriormente não era tão recorrente na sala de aula presencial. Tal fato se mostrou ainda mais evidente na resposta de duas alunas: "Sem a obrigatoriedade da descoberta de novos recursos tecnológicos, talvez eu não os procurasse por conta própria." e ainda: "Há momentos em que precisamos ser desafiados a aprender e utilizar novos recursos. ".

Assim, o uso das tecnologias de informação e comunicação de forma mais constante na formação dos futuros docentes, além de proporcionar o conhecimento de diferentes recursos e ferramentas, oportunizou a reflexão e a aprendizagem sobre sua utilização no processo ensino-aprendizagem, por meio da transposição didática, e não mais reservada ao estudo desenvolvido em uma única disciplina específica do currículo.

Inúmeras aprendizagens e saberes construídos, durante as aulas remotas com a ampliação do uso de recursos tecnológicos nas aulas, foram mencionados pelos estudantes do curso de Pedagogia, os quais, na visão deles, não teriam sido potencializados da mesma forma, nas aulas presenciais. Dentre estes saberes, destacam: "A própria utilização da 
tecnologia, sempre gostei mais de utilizar papel e caneta, mas aprendi a ter a tecnologia como minha aliada, utilizando recursos midiáticos." Neste sentido, outra estudante ressalta "a criação de diferentes estratégias pedagógicas; desenvolvimento de diferentes repertórios para interação virtual; prática da comunicabilidade, desembaraço na comunicação superando algumas dificuldades; disciplina." Foram mencionadas, ainda, habilidades como desenvolvimento de vídeos, elaboração de apresentações com mais recursos, comunicação, dentre outras.

Percebe-se, assim, que apesar de terem realizado disciplinas que abordaram diferentes conteúdos, a aprendizagem sobre o uso da tecnologia na educação se deu de forma bastante significativa, contribuindo para a formação dos futuros professores, que tiveram contato com diferentes possibilidades didáticas que estas apresentam, as quais poderão explorar em sua prática docente futura. Nesse sentido, os estudantes manifestaram as contribuições destes saberes para o desenvolvimento de "uma prática docente contemporânea", na qual temos "[...] as ferramentas digitais como uma aliada aos estudos, mesmo presencialmente na sala de aula.".

Assim, evidencia-se que não basta instrumentalizar os futuros docentes para o uso de recursos tecnológicos, mas proporcionar a reflexão e experimentação das diferentes possibilidades didáticas que estes oferecem para enriquecer o processo ensino-aprendizagem. Para Franco

Assim, cabe à Didática planejar e sistematizar a dinâmica dos processos de aprendizagem. [...] Caberá à Didática saber recolher, como ingredientes do ensino, essas aprendizagens de outras fontes, de outros mundos, de outras lógicas, para incorporá-las na qualidade de seu processo de ensino e na ampliação daquilo que se considera necessário para o momento pedagógico do aluno. (FRANCO, 2012, p. 151).

Nesta mesma direção, outra estudante viu na inserção das tecnologias de informação e comunicação na sala de aula a possibilidade de inovação da prática pedagógica, que permitirá uma maior aproximação à realidade dos alunos presentes na escola. Para ela, as tecnologias: "Permitirão a inovação nas aulas, formando pontes para estratégias pedagógicas mais alinhadas à demanda geracional dos estudantes.".

As "pontes para estratégias pedagógicas" mencionadas pela estudante permitem estabelecer um diálogo com o que Franco (2012, p. 150) aponta como o desafio da didática. 
Para a autora, a aprendizagem ocorre entre os múltiplos ensinos presentes na vida das pessoas, que muitas vezes, competem com o ensino escolar ou o potencializam. Neste contexto é que reside o desafio da didática: "tornar o ensino escolar tão desejável e vigoroso quanto os outros ensinos, potencializá-los, dialogar com eles."

A mobilização dos professores do curso de Pedagogia na organização das aulas remotas, mediadas pelo uso de tecnologias de informação e comunicação, contribuiu para a construção de saberes docentes que os futuros professores implementarão em suas práticas pedagógicas, especialmente quando se depararem com situações que exigirão deles repensar sua prática. Tal aspecto pode ser visualizado em uma das respostas dada por uma das alunas participantes do estudo, ao se referir às contribuições das aulas remotas para a sua formação docente: "Isso me fez enxergar que eu posso ir além da minha expectativa, posso me doar muito mais e levar muito mais recursos para sala de aula, estes que além de me auxiliar, também vão mostrar outras maneiras de passar o conhecimento."

Neste sentido, nos reportamos ao que aponta Franco, quando afirma que a Pedagogia precisa

[...] dialogar com a instabilidade e a urgência das circunstâncias que se apresentam à educação, à escola, aos professores. [...] Não basta à Pedagogia oferecer modos de fazer. É preciso oferecer modos de pensar e sentir, formas de criar e adaptar, perspectivas para saber lidar com processos que se organizam e se desconstroem a cada momento. (FRANCO, 2012, p. 216).

Por fim, outra respondente destacou o quanto as experiências com o uso de recursos tecnológicos vivenciadas durante a pandemia, contribuíram para que seu uso seja mantido mesmo com o retorno às aulas presenciais, devido às suas contribuições à aprendizagem.

Mesmo voltando às aulas presenciais, acredito que muitos desses recursos ainda serão utilizados, como fazer jogos online em sala de aula. Os alunos terão familiaridade com essas tecnologias e poderão fazer atividades utilizando-as. Também teremos facilidade ao fazer trabalhos em grupo, já que agora estamos acostumados com essas ferramentas, antes vídeo chamadas não eram comuns para a realização desses trabalhos, resultando em uma grande logística para estarem todos no mesmo local e no mesmo horário para realizá-los.

Isso posto, ao retomarmos as palavras de Perrenoud, ratificamos que este é um caminho sem volta. "A escola não pode ignorar o que se passa no mundo. Ora, as novas 
tecnologias da informação e da comunicação (TIC ou NTIC) transformam espetacularmente não só as maneiras de comunicar, mas também de trabalhar, de decidir, de pensar." (PERRENOUD, 2000, p. 123).

Com o presente estudo podemos inferir que, apesar das dificuldades enfrentadas no campo educacional, em decorrência da pandemia e das fragilidades que acabaram por tornarem-se, ainda, mais expostas, a necessidade de reinventar a sala de aula, por meio da utilização de tecnologias de informação e comunicação acabou por acelerar e potencializar o desenvolvimento desta competência e dos saberes a ela associados, tanto por parte dos formadores de professores, nas instituições de ensino superior, quanto dos futuros professores, estudantes de Pedagogia.

\section{Considerações finais}

A metamorfose da sala de aula, em decorrência da pandemia, ao mesmo tempo que expôs problemas presentes na escola e na formação de professores também acelerou o movimento de inserção das tecnologias de informação e comunicação no processo ensinoaprendizagem, que andava a passos lentos.

As escolas de educação básica se encontraram despreparadas diante dos desafios do novo contexto e os docentes universitários se viram obrigados a buscar alternativas para adaptação rápida de suas aulas ao modo virtual. Nesse contexto, foi necessária a utilização de diferentes tecnologias de informação e comunicação, ainda não tão frequentes nas aulas presenciais ou reservadas exclusivamente ao estudo em uma disciplina prevista no currículo especificamente para este fim. A necessidade real imposta pela pandemia levou docentes, muitas vezes acomodados em suas metodologias, a repensar seu planejamento, conhecer novas tecnologias capazes de promover a comunicação e interação entre os atores do processo ensino-aprendizagem, bem como de dinamizar a nova sala de aula.

No curso de Pedagogia o uso das tecnologias de informação e comunicação nas diversas disciplinas permitiu manter próximos estudantes e professores, dando continuidade ao processo de aprendizagem de diferentes conteúdos. Recursos tecnológicos antes não utilizados foram experimentados por professores e estudantes e novos sentidos foram atribuídos a velhos recursos, o que foi observado a partir dos relatos dos próprios estudantes. Assim, os futuros professores em formação puderam refletir sobre o uso didático de tais 
recursos no processo ensino aprendizagem, mesmo não sendo este o foco das disciplinas nas quais estavam matriculados.

Deste modo, durante o período pandêmico, além dos saberes específicos das disciplinas, os estudantes construíram saberes relacionados à didática ao vivenciarem diferentes estratégias de ensino com o uso de recursos tecnológicos que podem ser utilizados tanto em momentos virtuais quanto presenciais. Este movimento acabou por potencializar alguns saberes necessários à prática docente, dentre eles as inúmeras possibilidades de utilização das tecnologias de informação e comunicação no processo ensino-aprendizagem aliadas à capacidade de inovar as práticas pedagógicas, a partir do movimento constante de repensar, experimentar, refletir, agir, avaliar em um processo de formação contínua.

\section{REFERÊNCIAS}

ALVES, Alda Judith. O planejamento de pesquisas qualitativas em educação. Cadernos de Pesquisa, São Paulo (77), maio 1991. p.53-61. Disponível em: http://publicacoes.fcc.org.br/index.php/cp/article/view/1042/1050. Acesso em: 25 jun. 2021.

ANDRADE, Julia Pinheiro. SARTORI, Juliana. O professor autor e experiências significativas na educação do século XXI: estratégias ativas baseadas na metodologia de contextualização da aprendizagem. In: BACICH, Lilian. MORAN, José. Metodologias ativas para uma educação inovadora: uma abordagem teórico-prática. Porto Alegre: Penso, 2018.

BACICH, Lilian. Formação continuada de professores para o uso de metodologias ativas. In: BACICH, Lilian. MORAN, José. Metodologias ativas para uma educação inovadora: uma abordagem teórico-prática. Porto Alegre: Penso, 2018.

BACICH, Lilian. MORAN, José (Org.). Metodologias ativas para uma educação inovadora: uma abordagem teórico-prática. Porto Alegre: Penso, 2018.

Comisión Económica para América Latina y el Caribe (CEPAL). United Nations Educational, Scientific and Cultural Organization (UNESCO). La educación en tiempos de la pandemia de COVID-19. Disponível em: https://www.cepal.org/es/publicaciones/45904-la-educaciontiempos-la-pandemia-covid-19. Acesso em: 29 jun. 2021.

CORRADINI, Suely Nercessian; MISUKAMI, Maria da Graça Nicoletti. Práticas pedagógicas e o uso da informática. Revista Exitus, v. 3, n. 2, jul./dez., 2013, p. 85-92. Disponível

em: http://ufopa.edu.br/portaldeperiodicos/index.php/revistaexitus/article/view/152. Acesso em: 20 jun. 2021. 
FAVA, Rui. Educação 3.0: aplicando o PDCA nas instituições de ensino. São Paulo: Saraiva, 2014.

FLICK, Uwe. Introdução à metodologia de pesquisa: um guia para iniciantes. Porto Alegre: Penso, 2013.

FRANCO, Maria Amélia do Rosário Santoro. Pedagogia e práticas docentes. São Paulo: Cortez, 2012.

GHEDIN, Evandro. Currículo, civilização e prática pedagógica. In: GHEDIN, Evandro (Org.). Currículo e desenvolvimento sociocultural. Manaus: BK Editora, 2008.

Gusso, Hélder Lima et al. Ensino Superior em tempos de pandemia: diretrizes à gestão universitária. Educação \& Sociedade [online]. 2020, v. 41 Disponível em: https://doi.org/10.1590/ES.238957. Acesso em: 26 jun. 2021.

PATTON, Michael Quinn. Qualitative Research and Evaluation Methods. 3. ed. Thousand Oaks, CA: Sage, 2002.

PERRENOUD, Philippe. Dez novas competências para ensinar. Porto Alegre: Artmed, 2000.

RAMOS, Cíncia Acioli da Silva. BARRAGAN, Luciana Gavazzi. MASETTO, Marcos Tarciso. Educação a distância: monitores e professor, equipe responsável pela disciplina. In: ALMEIDA, Fernando José de. ALMEIDA, Maria Elizabeth B. de. SILVA, Maria da Graça Moreira da. (Orgs). De Wuhan a Perdizes: Trajetos educativos. São Paulo: EDUC, 2020.

SANTOS, Edméa. Mídias e tecnologias na educação presencial e a distância. Rio de Janeiro: LTC, 2016.

SOARES, Lucas de Vasconcelos; COLARES, Maria Lília Imbiriba Sousa. Educação e tecnologias em tempos de pandemia no Brasil. Debates em Educação, Maceió, v. 12, n. 28, p. 19-41, Set./Dez. 2020. ISSN 2175-6600. Disponível em: https://www.seer.ufal.br/index.php/debateseducacao/article/view/10157. Acesso em: 20 jun. 2021.

UNESCO. Mapa Interativo sobre o impacto da COVID-19 na Educação. Educação: da interrupção à recuperação. Disponível em: https://pt.unesco.org/covid19/educationresponse. Acesso em: 29 jun. 2021.

VAZ, Douglas; MEINHARDT, Moana; FOSSATTI, Paulo. CAPÍTULO 3 A EXPERIÊNCIA GOOGLE FOR EDUCATION NA UNIVERSIDADE LA SALLE: DA IMPLANTAÇÃO À REINVENÇÃO A PARTIR DA PANDEMIA. Empreendedorismo e Inovação na Universidade La Salle, p. $17 . \quad$ Disponível em: https://revistas.unilasalle.edu.br/index.php/books/article/download/8501/3229\#page=17. Acesso em: 26 jun. 2021. 


\section{OO DEVIR EDUCAÇÃO}

ISSN: 2526-849X

YIN, Robert K. Estudo de caso: Planejamento e métodos. $5^{\circ}$ ed. Porto Alegre, RS: Bookman, 2015.

ZANELLI, José Carlos. Pesquisa qualitativa em estudos da gestão de pessoas. Estudos da Psicologia, n. 7, p. 79-88, 2002. Disponível em: https://www.scielo.br/j/epsic/a/GdRk6zHHNz4yL6NBsH6P4yH/?lang=pt\&format=pdf. Acesso em: 29 jun. 2021.

Recebido em: 30/06/21

Aprovado em: 23/08/21 